\title{
O Óxido Nítrico, uma Molécula Versátil
}

\author{
RICARDO FRA NCO E ALICE S. PEREIRA *
}

O óxido nítrico, NO, é uma molécula pequena, relativamente instável e potencialmente tóxica. Embora tenha sido desde há muito estudado como um sub-produto reactivo da queima de combustíveis fósseis, foi só recentemente que este radical livre diatómico se tornou numa das moléculas mais estudadas, devido ao seu protagonismo em sistemas biológicos.

\section{A QUímICA DO NO}

$\mathrm{O}$ óxido nítrico (NO) é um gás incolor, moderadamente solúvel em água (a saturação ocorre a $2 \mathrm{mM}$ de gás) e pertence a uma família de compostos, os óxidos de azoto, que são bastante diferentes entre si do ponto de vista de estrutura e reactividade. O NO é o membro mais simples dessa família: é um radical diatómico, paramagnético e com um comprimento de ligação N-O igual a 1,15 Å, um valor intermédio entre uma ligação tripla (1,06 ̊) e uma ligação dupla típica (cerca de 1,20 ̊), o que faz com que o NO tenha uma ordem de ligação de 2,5 .

O NO pode ser sintetizado no laboratório, pela acidificação do nitrito de sódio na presença de um agente redutor, que pode ser o ião ferroso, de acordo com a seguinte reacção:

$$
\mathrm{NO}_{2}^{-}+\mathrm{Fe}^{2+}+2 \mathrm{H}^{+} \rightarrow \mathrm{NO}+\mathrm{Fe}^{3+}+\mathrm{H}_{2} \mathrm{O}
$$

Numa escala industrial, o NO é produzido pela oxidação da amónia na presença de um catalisador metálico ou por passagem de um fluxo de ar através de um arco eléctrico.

A natureza dos produtos de oxidação do NO depende do meio reaccional. Enquanto que em fase gasosa o NO reage com o oxigénio molecular para gerar dióxido de azoto $\left(\mathrm{NO}_{2}\right)$, em fase aquosa é produzido nitrito $\left(\mathrm{NO}_{2}^{-}\right)$e em certas culturas celulares produtoras de NO podem ser detectados tanto nitrito como nitrato $\left(\mathrm{NO}_{3}^{-}\right)$.

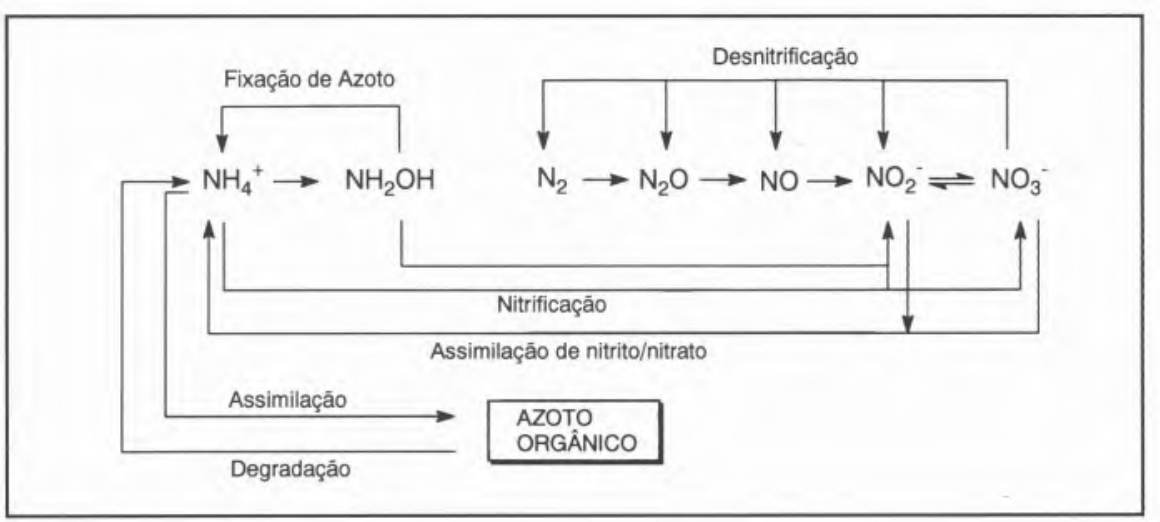

Fig. 1 - Ciclo do Azoto (adaptado da referência 10).

\section{O PAPEL DO NO COMO AGENTE POLUENTE}

Nos motores de combustão interna são produzidos diferentes óxidos de azoto $\left(\mathrm{NO}_{\mathrm{X}}\right)$ pela combinação directa de $\mathrm{N}_{2}$ e $\mathrm{O}_{2}$ a temperaturas elevada. Os gases deste modo produzidos são considerados, juntamente com o $\mathrm{SO}_{2}$, como os poluentes atmosféricos responsáveis pela formação de "smog" fotoquímico e de chuvas ácidas.

Como seria de prever, os países industrializados são os grandes responsáveis pelas emissões mundiais de $\mathrm{NO}_{\mathrm{X}}$. Na União Europeia, por exemplo, em 1985, 77\% das emissões totais de $\mathrm{NO}_{\mathrm{X}}$ foram da responsabilidade, por ordem decrescente, da Alemanha, Reino Unido, França e Itália, estando Portugal em décimo lugar com apenas $0,9 \%$ do total das emissões (1).

Os governos dos países industrializados, preocupados com as crescentes emissões de $\mathrm{NO}_{X}$, têm vindo a tomar medidas conducentes à sua diminuição, das quais são exemplos a busca de fontes de energia alternativas aos combustíveis de origem vegetal e a utilização de catalisadores nos veículos automóveis. De facto, o sector dos transportes é responsável, por si só, por $40 \%$ do total das emissões mundiais que serão de cerca de 90 milhões de toneladas em 1995 (previsões da Agência Internacional de Energia) (2).

\section{O PAPEL DO NO EM SISTEMAS BIOLÓGICOS}

Até 1981 pensava-se que a biossíntese do NO se restringia a bactérias envolvidas em reacções de nitrificação/desnitrificação, mecanismos fundamentais para a fixação biológica de azoto (Figura 1).

No entanto, estudos recentes envolvendo macrófagos (células do sistema imunitário de mamíferos, que desempenham um papel importante na defesa contra tumores e infecções), provaram que estas células são capazes de produzir NO através da oxidação enzimática específica do ácido-aminado L-arginina na presença de NADPH (o NADP - dinucleótido fosfatado de nicotinamida e adenina, aqui na sua forma reduzida, é um mediador redox por excelência em sistemas biológicos), dando origem, para além de NO, a L-citrulina e a NADP+ (a forma oxidada do NADP) (3-6) (Figura 2). Esta via metabólica de produção de NO, por células de mamíferos, é catalisada pela sintetase do óxido nítrico ( $\mathrm{SON}$, ou NOS na notação inglesa). Todos os tipos de SON estudadas até ao momento contêm quatro grupos prostéticos: um dinucleótido de flavina e adenina (FAD), um mononucleótido de flavina (FMN), uma tetra-hidro-bio-pterina $\left(\mathrm{H}_{4}\right.$ biopterina) e finalmente um grupo hemo (ferro-protoporfirina IX) (Figura 3). A proteína é funcional na forma dimérica, contendo cada subunidade 
os quatro co-factores. Embora todos estes co-factores possam ser encontrados em vários sistemas biológicos $\mathrm{e}$ catalisem um elevado número de reacções de oxidação e de redução, a SON é a única enzima conhecida que necessita da presença simultânea dos quatro grupos para ser funcional. Estudos por via genética da sequência de ácidos-aminados da SON sugerem uma relação entre a sequência detectada e o desempenho de funções enzimáticas. De facto, cada subunidade da enzima encontra-se dividida num domínio de redutase e num domínio de oxidase. A ligação entre ambos os domínios é efectuada por um local de ligação para a calmoduli- na, enzima que necessita de ião cálcio $\left(\mathrm{Ca}^{2+}\right)$ para funcionar e que está envolvida em processos biológicos tão importantes como a contracção muscular ou a transmissão de impulsos nervosos. A relação entre a calmodulina e a SON é presentemente objecto de estudos aprofundados com vista a elucidar até que ponto a ligação da primeira tem influência na actividade da segunda.

É interessante notar que o domínio de redutase da SON contém os locais de ligação para os co-factores FAD e FMN e para o agente redutor (NADPH). A sequência de ácidos animados deste domínio é semelhante à de outras enzimas que pos-

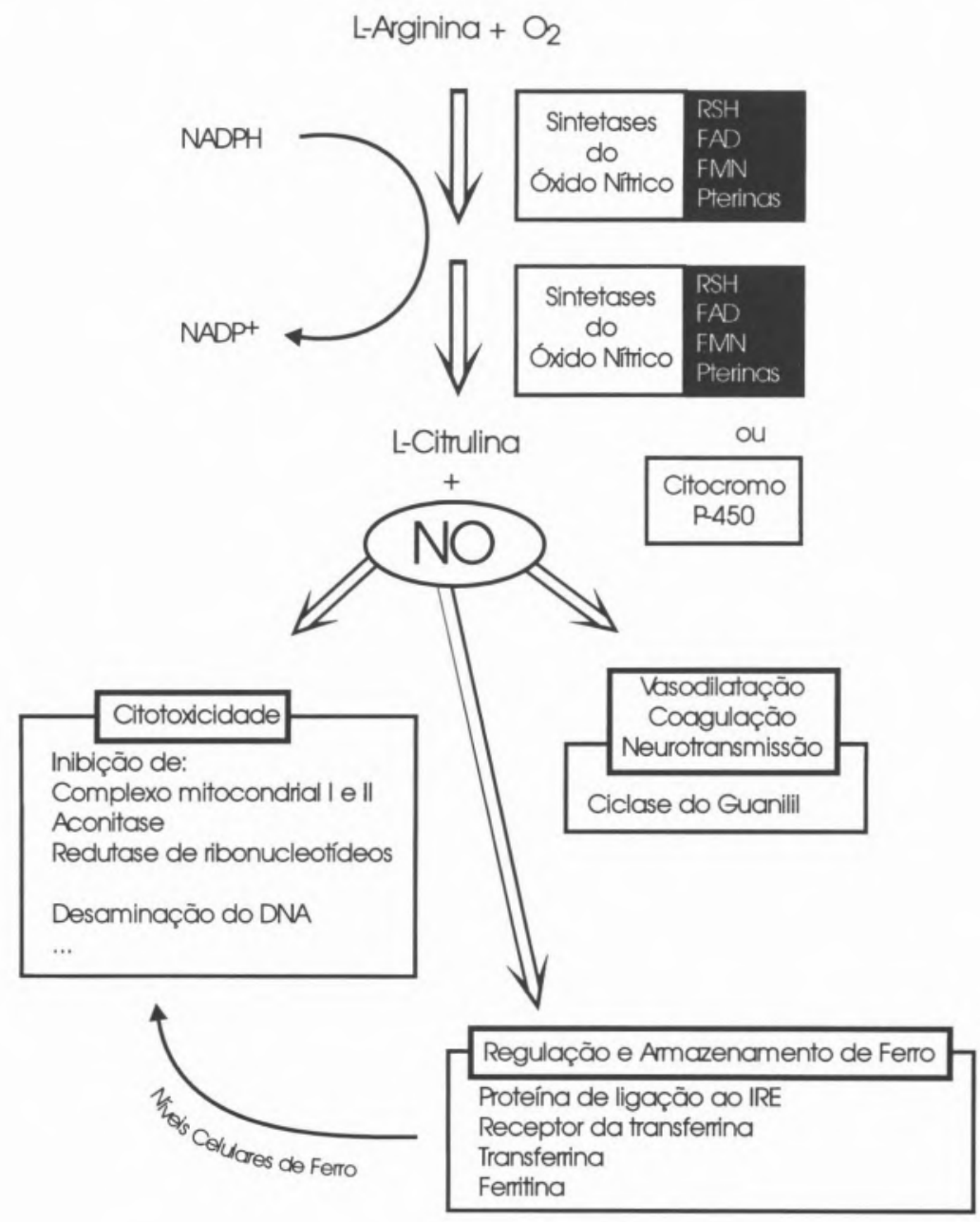

Fig. 2 - O papel do NO em sistemas biológicos (adaptado da referência 11)

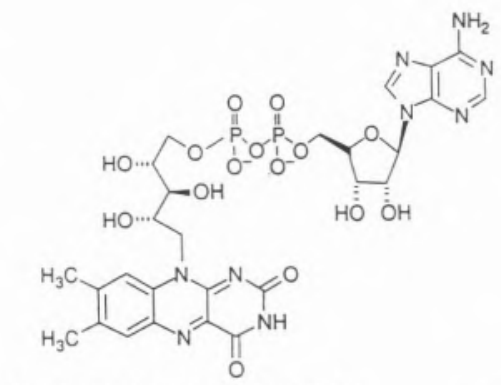

Dinucleótido de Flavina e Adenina (FAD)

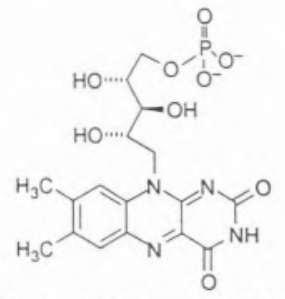

Mononucleótido de Flavina (FMN)
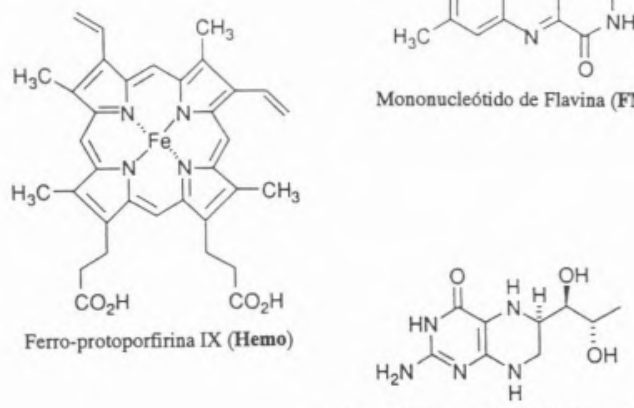

Tetrahidro bio-pterina $\left(\mathrm{H}_{4}\right.$ biopterina

Fig. 3 - Os co-factores da sintetase do óxido nítrico (SON).

suem este tipo de co-factores e que estão envolvidas em reacções de redução, tais como a redutase do citocromo $\mathrm{P}_{450}$ de mamífero ou a redutase do sulfito de E. coli. O domínio de oxidase da SON possui então locais de ligação para o substrato, Larginina, assim como para os grupos $\mathrm{H}_{4}$ biopterina e hemo. Pensa-se que este último co-factor desempenha um papel determinante no processo catalítico de síntese do NO.

O principal papel desempenhado pelo NO a nível biológico é o de mensageiro. Mas como mensageiro e pelo facto de ser um gás, apresenta a particularidade de se difundir livremente pela célula em todas as direcções, sem estar dependente de transportadores ou canais específicos. A sua intervenção verifica-se a vários níveis, nomeadamente na transmissão nervosa, na coagulação sanguínea, no controlo da pressão arterial e a nível imunitário, onde apresenta a capacidade de matar células cancerosas e parasitas intrace- 
lulares (Figura 2).

Entre as mais importante funções do NO a nível biológico, destaca-se a sua interacção com o ligando $\mathrm{O}_{2}$ da oxi-hemoglobina. A interacção leva à produção da forma inactiva, a meta-hemoglobina, diminuindo o transporte de oxigénio para a célula. Uma vez que a maior parte das células se encontra na proximidade de vasos capilares contendo glóbulos vermelhos, a probabilidade do NO encontrar uma molécula de oxi-hemoglobina e com ela reagir, é muito elevada.

O metabolismo do NO in vivo resulta, também, na formação de uma série de compostos nitrosotióis de alto e baixo peso molecular. A $S$-nitrosoglutationa e a $S$-nitrosocisteína, são exemplos de $S$-nitrosotióis biológicos que são conhecidos como transportadores de $\mathrm{NO}$ em animais.

Como neurotransmissor, pensa-se que o papel do NO é o de um mensageiro retroactivo, i.e., após uma sinapse nervosa, o NO difundiria para o neurónio de onde tinha sido originado o impulso e ligar-se- ia, aí, ao hemo da enzima ciclase do guanilil, activando-a. Esta enzima converte GTP (trifosfato de guanosina), o principal mensageiro molecular celular, a cGMP (monofosfato cíclico de guanosina), o segundo mais importante mensageiro celular, pelo que a síntese de cGMP seria assim aumentada. Esta hipótese de um mecanismo retroactivo tem especial interesse devido ao seu possível envolvimento nos processos cerebrais de memória. O NO é ainda mediador de certos neurónios do sistema nervoso periférico que apenas são sensíveis ao NO mas não aos neurotransmissores "normais" (a acetilcolina e a norepineferina). Foram também detectados neurónios deste tipo nos sistemas cardiovascular, urogenital, respiratório e digestivo.

Ao nível da regulação da pressão sanguínea, é necessária a síntese constante de NO pelas células do endotélio vascular de modo a garantir uma pressão sanguínea normal. De facto, vários estudos têm demonstrado que os músculos vasculares não relaxam devidamente quan- do não é produzido NO a um ritmo nonnal, quer devido à produção de NO ter sido bloqueada pela administração de um inibidor da SON, quer em estados patológicos tais como a arterioesclerose. Refira-se a propósito a nitroglicerina, uma substância vasodilatadora que in vivo liberta NO, muito utilizada no tratamento de doenças cardiovasculares dadas as suas propriedades vasodilatadoras, diminuidoras da pressão arterial e de aumento da corrente sanguínea. Estudos efectuados por Ignarro vieram demonstrar que o mecanismo molecular de acção farmacológica da nitroglicerina se baseava na formação de S-nitrosotióis como precursores do NO (7).

Como agente citotóxico, o óxido nítrico pode provocar danos a nível celular ao atacar os centros de ferro-enxofre de certas proteínaschave do metabolismo, nomeadamente na aconitase, uma enzima do Ciclo de Krebs que, na sua forma activa contém um centro de [4Fe-4S] (8). De facto, o NO é uma molécula que apresenta elevada afi-

\section{DETECÇÃO DE ÓXIDO NÍTRICO GERADO BIOLOGICAMENTE}

Existem várias técnicas experimentais que possibilitam seguir a produção de óxido nítrico e que detectar a sua libertação a partir de substâncias exógenas em sistemas biológicos:

\section{(1) Quimioluminescência}

Trata-se de uma técnica que permite a análise do NO em fase gasosa. A amostra biológica pode ser purgada por um gás arrastador inerte (p.e., azoto) de modo a libertar para a fase gasosa o NO produzido. A oxidação do NO com ozono, produz dióxido de azoto num estado excitado que, ao relaxar para o esta- do fundamental, emite luz com uma energia característica que pode ser facilmente detectada por um tubo fotomultiplicador. Esta técnica tem como vantagem o facto do NO poder ser detectado directamente e com grande sensibilidade. A maior desvantagem deste método está associado ao facto do NO ter que ser removido do meio biológico, remoção essa que pode nem sempre ser perfeitamente quantitativa. No caso de amostras sanguíneas torna-se extremamente difícil remover NO dada a sua grande afinidade e reactividade com a hemoglobina.

\section{(2) Ensaios baseados na reacção de Griess}

Este ensaio baseia-se na capacidade que o NO tem de ser oxidado a nitrato ou nitrito em condições fisiológicas. As soluções de nitrato e nitrito assim obtidos, são inicialmente reduzidas a nitrito através, p.e., da utilização da enzima bacteriana redutase do nitrato. A solução resultante é reagida com sulfanilamida numa solução acidificada de dihidrocloreto de $\mathrm{N}$-(1-naftil)etilenodiamida, o que leva ao aparecimento estequiométrico de um derivado azo que pode ser detectado a $548 \mathrm{~nm}$ por espectrofotometria. Este ensaio, também conhecido como reacção de Griess, é o normalmente usado para detectar NO produzido biologicamente, dado a reacção em que se baseia ser completa e estequiométrica e também por ser um método simples e de elevada sensibilidade. No entanto, a técnica não mede directamente o NO produzido mas 

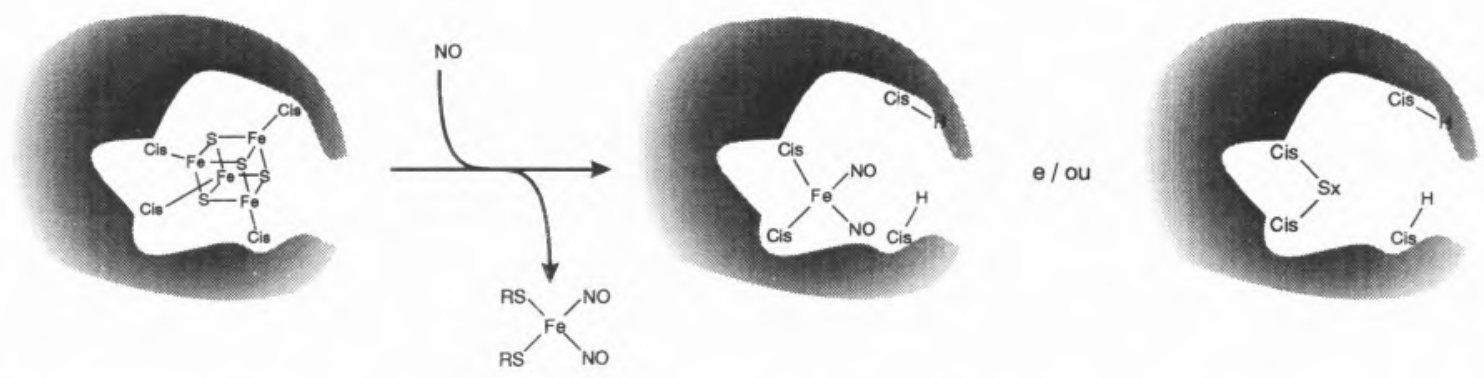

Fig. 4 - Mecanismo hipotético da interacção do NO com um centro de ferro-enxofre do [4Fe4S]. A ligac,ão do centro à cadeia polipeptídica é mediada por 4 resísuos de cisteína que coordenam cada um dos átomos de ferro do cubo (adaptado da referência 12).

nidade para metais de transição, em particular para o ferro e para o cobre. A interação do NO com proteínas de ferro-enxofre foi descrita pela primeira vez por Salerno e colaboradores em 1976 (9). Pela aplicação da espectroscopia de Ressonância Paramagnética Electrónica (R.P.E.), técnica por excelência para a detecção de NO (vide caixa). os autores caracterizaram espectroscopicamente o complexo proteína-NO, com a finalidade de determinar o número e o arranjo es- trutural dos átomos de ferro presentes. Na figura 4, apresenta-se um mecanismo hipotético da interacção da molécula de NO com uma proteína de ferro-enxofre, que neste caso contém um centro do tipo [4Fe-4S]. Neste mecanismo a interacção implica a destruição do centro de ferro-enxofre e a formação de derivados de ferro sulfo-nitrosilados, quer solúveis, quer ligados à proteína. Estes derivados podem ser detectados através dos seus espectros de R.P.E. típicos. A estrutura apresentada mais à direita, ainda na figura 4 , representa a possibilidade, ainda não provada, da formação de um poli-sulfureto à custa do enxofre inorgânico libertado no processo de destruição do centro de ferro-enxofre.

\section{PERSPECTIVAS FUTURAS}

Enquanto que, por um lado, o mundo industrializado se preocupa em controlar os níveis de emissões atmosféricas de óxidos de azoto e é posta em evidência a sua elevada apenas nitrato e nitrito que representam os derivados estáveis do NO produzido em mamíferos. Assim, esta técnica não distingue entre o nitrato ou nitrito produzidos pelo metabolismo do NO daquele proveniente de outras fontes.

\section{(3) Espectroscopia de Ressonância Paramagnética Electrónica (R.P.E.)}

O NO é uma molécula paramagnética, possuindo um número quantico de spin semi-inteiro $(\mathrm{S}=1 / 2)$ que corresponde a um electrão desemparelhado por molécula, possibilitando a sua detecção por aplicação da espectroscopia de R.P.E. (uma técnica que detecta electrões desemparelhados) em soluções aquosas, células e tecidos. $\mathrm{O}$ método baseia-se na formação de um complexo estável de NO, o [NOFe(DETC $)_{2}$ ], obtido pela incubação da amostra contendo NO com Fe(II)-DETC (dietiltiocarbamato de ferro). A produção deste complexo pode ser seguida quantitativamente por R.P.E. utilizando a calibração com um padrão (geralmente o CuEDTA, que apresenta 1 electrão desemparelhado por molécula). A maior vantagem desta técnica é que permite a detecção directa da produção de NO. A sua maior desvantagem, além da necessidade de equipamento adequado, é a de apenas poder ser feita a detecção em meios hidrofóbicos, uma vez que o complexo formado como NO não é solúvel em água.

\section{(4) Espectrofotometria por monitorização da meta-hemoglobina}

A base para este ensaio consiste na detecção espectrofotométrica da meta-hemoglobina formada aquando da reacção do NO com a oxi-hemoglobina. De facto, a reacção rápida do NO com a oxi-hemoglobina $\left(\mathrm{HbO}_{2}\right)$ para gerar meta-hemoglobina $\left(\mathrm{Hb}^{+}\right)$e ião nitrato, leva a um deslocamento da banda de visível de $415 \mathrm{~nm}$ para $405 \mathrm{~nm}$. Embora este método permita não apenas uma detecção do NO formado de modo quantitativo mas também um acompanhamento dessa formação ao longo do tempo, apresenta as desvantagens de, por um lado, o mecanismo da 
toxicidade, por outro são descobertas as mais variadas e excitantes funções biológicas para este radical livre diatómico.

Embora a descoberta da existência de um papel importante para o NO em sistemas biológicos tenha sido feita há apenas dez anos, os progressos na elucidação das suas múltiplas funções têm sido notáveis. No entanto, numerosos enigmas continuam a existir: as funções do NO a nível do cérebro são intrigantes e continuam a levantar grande polémica; as funções desta pequena molécula a nível dos vasos sanguíneos e de outros tecidos estão longe de se encontrarem perfeitamente esclarecidas. O próprio mecanismo de funcionamento da sintetase do óxido nítrico (SON), a enzima responsável pela produção de NO in vivo, coloca grandes desafios. Outro tópico de grande interesse e actualidade consiste no estudo dos mecanismos pelos quais o NO destrói determinadas células, nomeadamente cé-

(...) reacção envolvida não ser bem compreendido e por outro, haver um erro considerável nas medidas devido à contribuição de outras formas de hemoglobina na região do visível.

\section{(5) Oxidação electroquímica}

Estudos recentes levaram ao desenvolvimento de uma técnica de electroquímica que se baseia na capacidade que o NO tem de ser oxidado a nitrato, de modo a seguir quantitativamente a formação do NO em amostras biológicas. O ânodo e o cátodo são introduzidos na amostra em estudo, sendo o NO desta oxidado no ânodo. A corrente gerada é proporcional à quantidade de NO que foi oxidado: lulas cancerosas e o seu mecanismo de acção ao provocar a desagregação dos centros de ferro-enxofre, grupos prostéticos essenciais de determinadas enzimas-chave do metabolismo.

Por um lado um radical livre altamente tóxico, por outro um efector biológico de importância fundamental, é esta a surpreendente vida dupla do óxido nítrico.

\section{* Departamento de Química e Centro de Química Fina e Biotecnologia, Faculdade de Ciências e Tecnologia, Universidade Nova de Lisboa, 2825 Monte da Caparica}

\section{REFERÊNCIAS}

1. Plano Energético Nacional, Parte III, Secretaria de Estado da Energia do MIE, 1992.

2. OCDE/IEA, in "Greenhouse gas emissions, the energy dimension", 1991.

$$
\mathrm{NO}+40 \mathrm{H}^{-} \rightarrow \mathrm{NO}_{3}^{-}+2 \mathrm{H}_{2} \mathrm{O}+3 e^{-}
$$

De modo a evitar a ocorrência de outro tipo de oxidações, ambos os eléctrodos são envolvidos numa película que é apenas permeável a gases. Esta técnica é a única que apresenta a vantagem de permitir a medição de concentrações momentâneas de NO. Qualquer dos outros métodos mede o NO produzido em determinado intervalo de tempo (embora este possa ser bastante reduzido para o caso da Espectrometria de Massa). As desvantagens desta técnica prendem-se com possíveis interferências químicas e eléctricas.

\section{(6) Espectrometria de Massa}

A Espectrometria de Massa aplicada à detecção de gases gera
3. Stamler, J.S., Singel, D.J. e Loscalzo, J. (1992) Science 258, 1898-1902.

4. Feldman, P.L., Griffith, O.W. e Stuehr, D.J. (1993) Chemical and Engineering News 71, 2638.

5. Zumft, W.G. Arch. Microbiol. 160, 253-264.

6. Snyder, S.H. (1992) Science 257, 494-496.

7. Ignarro, L.J. (1990) Ann. Rev. Pharmacol. Toxicol. 30, 535-560.

8. Emptage, M.H. (1988) in "Metal Clusters in Proteins" (Que, L., Jr., ed.) pp. 343-371, American Chemical Society, Washington DC.

9. Salerno, J.C., Ohnishi, T., Lim, J. e King, T.E. (1976) Biochem. Biophys. Res. Commun. 73, 833840 .

10. Burgmayer, S.J.N. e Stiefel, E.I. (1985) J. Chem. Ed. 62, 943 .

11. Henry, Y., Drucocq, C., Drapier, J.-C., Servent, D., Pellat, C. e Guissani (1991) Eur. Biophys. J. 20, 1-15.

12. Beinert, H. (1990) FASEB 1. 4, 2483.

dos por amostras biológicas baseiase na utilização de uma célula reaccional contendo uma membrana porosa que apenas é permeável a gases. A amostra biológica em estudo é colocada nesta célula e os gases produzidos difundem através de um sistema de alto vácuo para uma camara de ionização, sendo em seguida detectados os diferentes iões assim gerados. Este método apresenta elevada sensibilidade e selectividade (apenas é seguido o pico correspondente à massa do ião de interesse, o $\mathrm{NO}^{+}, 30$ u.m.a.) e é capaz de detectar todo o NO produzido por qualquer amostra biológica. Além disso, permite um acompanhamento da produção de NO para intervalos de tempo muito curtos. A única desvantagem deste método consiste na necessidade de equipamento adequado. 
(PMT) TAMSON
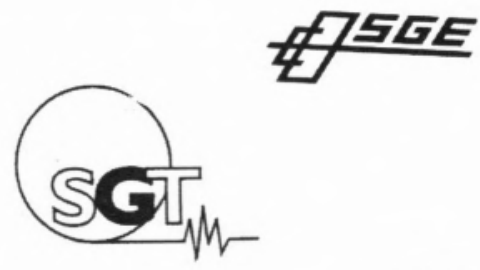

\section{METTLER TOLEDO}

\section{FisherScientific}
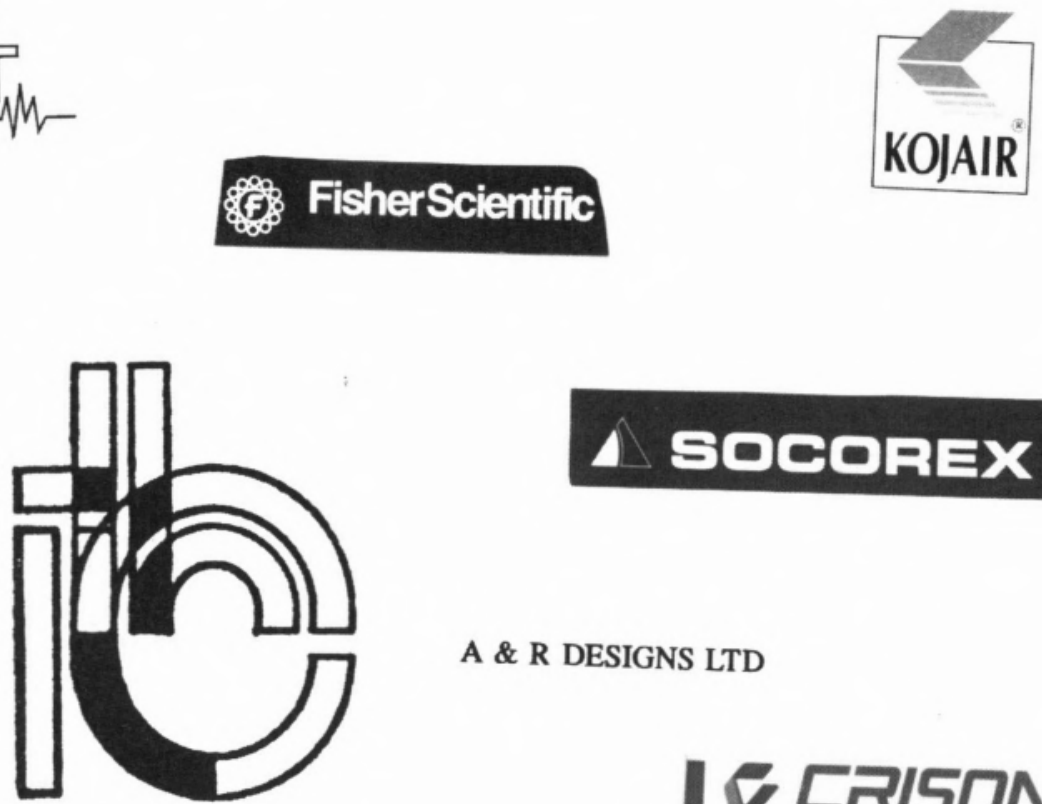

\section{$\triangle$ GDCOFEX}

Hansatech

A \& R DESIGNS LTD

\section{E CRISDN}

\section{Alltech}

UNIEQUIP
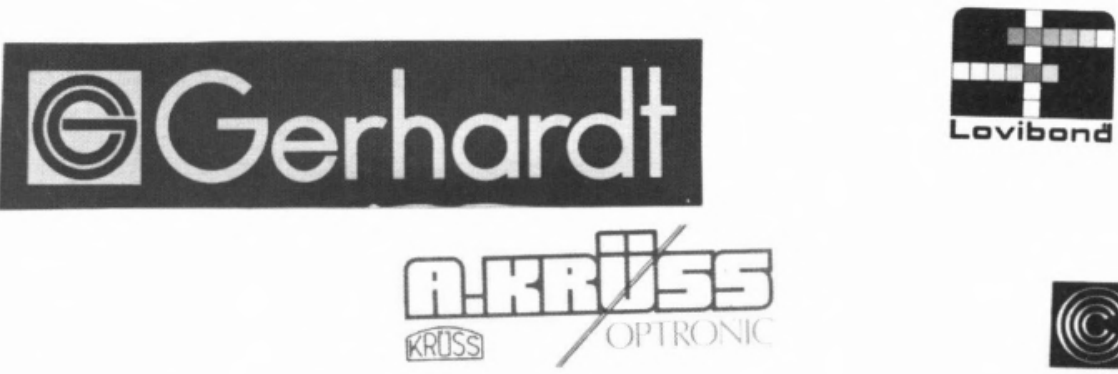

Cathodeon

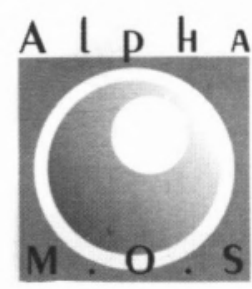

Promochem 